\title{
Freie Luft im Abdomen?
}

\section{Dr. Katrin Kipke}

Ärztin, Radiologie, Städtisches Klinikum Dresden-Neustadt Katrin.Kipke@khdn.de

\section{Zum Mediquiz Fall 3170, DMW 5/2014}

In die Auflösung des Falles 3170 hat sich ein Fehler eingeschlichen. Pfeil 4 zeigt im linken Bild (koronare Schnittführung) auf Luft im Thorax, oberhalb des Zwerchfells. Dort darf Luft sein, aber nicht im Bauchraum zwischen linken Leberlappen und Magen im selben Bild.

\section{Erwiderung}

\section{Dr. med.}

Andreas Gunter Bach Klinik für Diagnostische Radiologie

Martin-Luther-Universität Halle-Wittenberg mail@andreas-bach.de

Dr. med. Rick Schneider Klinik für Allgemein-, Viszeral-, und Gefäßchirurgie Martin-Luther-Universität Halle-Wittenberg rick.schneider@uk-halle.de

\section{Hinweis}

Der Beitrag „Bach AG, Schneider R. Reißende thorakale Schmerzen bei einem 67-jährigen Mann. Dtsch Med Wochenschr 2015; 140: 314“, auf den sich die Leserzuschrift bezieht, wurde berichtigt. Online ist die korrekte Abbildung verfügbar: http://dx.doi.org/ 10.1055/s-0041-100714

DOI 10.1055/s-0041-102337 Dtsch Med Wochenschr 2015; 140: 962

(c) Georg Thieme Verlag KG . Stuttgart · New York . ISSN 0012-0472
Die Kollegin hat recht; bei der Auszeichnung des Bildes hat sich bedauerlicherweise ein Fehler eingeschlichen: Die „4“ in der axialen Ebene ist korrekt. Die „4“ in der koronaren Ebene bezeichnet nicht den selben Lufteinschluss. Dies erkennt man daran, dass in der axialen Ebene die Luft fast mittig ist, in der koronaren Ebene die (fälschlicherweise markierte) 4 ganz seitlich liegt.

Zum besseren Überblick sind die anatomischen Strukturen in Abb. 1 markiert:

Das Zwerchfell ist als dünne Struktur zu erkennen, welche Thorax und Abdomen trennt. Mittig dem Zwerchfell sitzt das Herz auf. In seiner Umgebung findet sich mediastinales Fettgewebe. Durch die koronare Schnittführung erscheinen thoraxwandnahe Fettlamellen und fettige Verschwielungen an der Basis der Lunge im Bild sehr prominent (f). Aufgrund der Darstellung im
Weichteilfenster zeigt sich normales Lungengewebe (a) und freie Luft gleichermaßen als schwarz. Das im Bild erfasste Lungengewebe erreicht im rechten Recessus costodiaphragmaticus punktförmig die koronare Bildschicht (roter Pfeil). Es handelt sich aber nicht - wie zuerst fälschlicherweise bezeichnet - um einen Lufteinschluss.

Weiterhin weisen Darmanteile (g) einzelne, dünnwandige Divertikel auf, welche als Bläschen in Darmnähe zu sehen sind. Tatsächlich ist nur an zwei Stellen freie intraabdominelle Luft nachweisbar, nämlich direkt an der Perforationsstelle des Magens (c ) und als kleine Luftblase in unmittelbarer Nähe (als gelber Punkt markiert). Der perforierte Magen (b) und die Leber (d) sind aufgrund ihrer Lage gut abgrenzbar. Zwischen Leber und Zwerchfell findet sich Aszites (e).

Abb. 1 Kontrastmittel-gestützte Computertomographie des Thorax und Abdomens in koronarer Schnittführung.
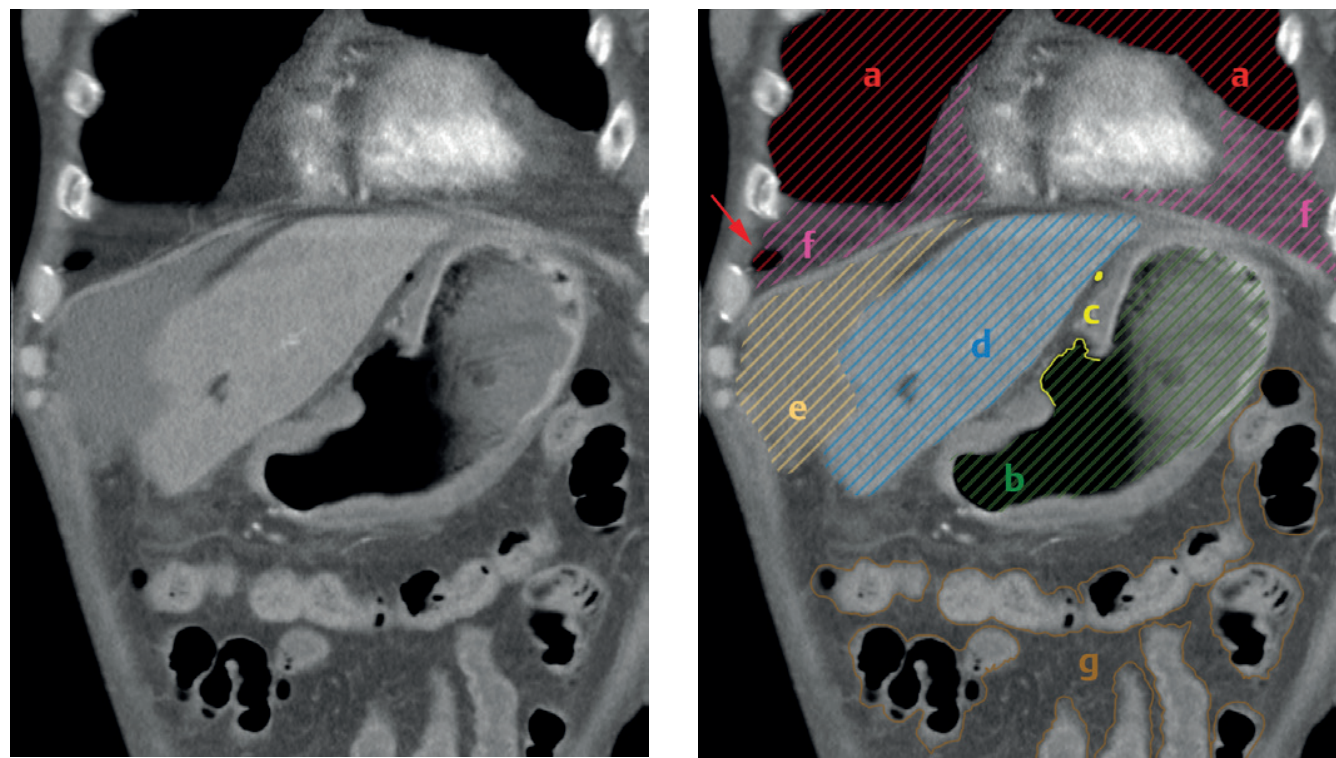